\title{
Torpor, arousal and activity of hibernating greater horseshoe bats \\ (Rhinolophus ferrumequinum)
}

\author{
Kirsty J. Park ${ }^{1}$, Gareth Jones ${ }^{2}$ and Roger D. Ransome ${ }^{2}$ \\ ${ }^{1}$ Department of Biological Sciences, University of Stirling, Stirling FK9 4LA, U.K. \\ ${ }^{2}$ School of Biological Sciences, University of Bristol, Bristol BS8 1UG, U.K.
}

Short title: Torpor, arousal and activity in bat hibernation

${ }^{1}$ Address for correspondence: Dr Kirsty Park, Avian Ecology Unit, Department of Biological Sciences, University of Stirling, Stirling FK9 4LA

Tel. (01786) 467799

Fax (01786) 464994

e-mail K.J.Park@stir.ac.uk 


\section{SUMMARY}

1. Patterns of torpor, arousal, and activity in free-living greater horseshoe bats, Rhinolophus ferrumequinum, were investigated during the hibernation period by using temperature-sensitive radio-transmitters.

2. Torpor bouts varied between 0.1 - 11.8 days, with individual means ranging from 1.3 - 7.4 days. Torpor bout duration decreased with increasing ambient temperature.

3. Activity duration varied from 37 minutes -54 hours 24 minutes, with individual means ranging from 2:29 to 8:58 hours. Activity duration increased with ambient temperatures above approximately $10^{\circ} \mathrm{C}$.

4. Ten of 11 bats synchronised their arousals with dusk. The circadian rhythm of one bat showed a free-running pattern over a period of about five weeks. Arousals were more highly synchronised, and closer to dusk, in individuals with lower body condition.

5. That bats forage in mild weather is supported by the strong synchronisation of arousals with dusk, especially in bats with low body condition.

6. Patterns of torpor and subsequent activity are consistent with predictions that torpor lasts until a critical metabolic or water imbalance is achieved. Because metabolism and water loss are temperature-dependent, torpor bout duration decreases with increasing temperature. The imbalance is corrected during subsequent activity, which is relatively constant in duration until a temperature threshold of $10^{\circ} \mathrm{C}$, above which increasing levels of foraging lead to longer activity bouts.

KEYWORDS: circadian rhythms, foraging, hibernation, radio-telemetry 


\section{INTRODUCTION}

Many species of small, temperate zone mammal spend much of the winter in hibernation, minimising their energy expenditure when there is little or no food, and when ambient temperatures are generally low (see Lyman 1982; Malan 1989 for reviews). All hibernating mammals studied, however, arouse periodically throughout winter by boosting the metabolism of brown adipose tissue to generate the extra heat needed to increase body temperature (Trayhurn 1993).

Much attention has focused on why mammals arouse from hibernation torpor, it is energetically costly to do so (Thomas, Dorais \& Bergeron 1990). Hence arousals are assumed either to have direct functional significance, or permit important events to occur during subsequent activity. Suggested functions include: 1) to drink (Fisher \& Mannery 1967; Speakman \& Racey 1989; Thomas \& Cloutier 1992; Thomas \& Geiser 1997); 2) to urinate or restore some metabolic imbalance (see Willis 1982 for a review); 3) to repay sleep deprivation, as the normal restorative function of sleep may be inhibited by low brain temperatures (Daan, Barnes \& Strijkstra 1991; Trachsel, Edgar \& Heller 1991); 4) to resist disease (Schmidt 1967 but see also Burton \& Reichman 1999). Additionally, and especially for bats, arousals may provide opportunities for feeding (Ransome 1968, 1971; Avery 1985; Brigham 1987), for reproductive activity (Tidemann 1982), and for roost site selection (Ransome 1968, 1971).

Ransome (1971) suggested that the bat Rhinolophus ferrumequinum (Schreber) selects roost temperatures that result in the most advantageous arousal frequency in relation to expected foraging success. Furthermore, bats selected roost regions whose temperature fluctuated with ambient temperatures, allowing synchrony of arousals with warm nights (Ransome 1968, 1971).

Laboratory studies of hibernation and arousal have often produced findings that do not occur under natural conditions, perhaps because the stress and conditions in captivity alter the natural pattern of torpor and arousal (Thomas 1995). It is therefore important to understand the patterns of torpor and arousal under natural conditions. Such information on arousal patterns is lacking for most 
hibernators (but see Wang 1978; Young 1990; Michener 1992), and has not previously been documented for free-living bats.

In this study we investigated patterns of torpor and arousal using radio-telemetry to monitor the body temperature and movements of bats in the wild. We have two main aims. The first is to document arousal patterns of free-living $R$. ferrumequinum, and its behaviour following arousals, over the hibernation period. The second is to make inferences about the function of arousals and subsequent activity. French (1985) proposed that euthermic activity after arousal functions to restore metabolic imbalances developed during the previous torpor bout. If this is correct, we predict that, in accordance with findings of previous studies (e.g. Twente \& Twente 1965), torpor bout duration should decrease with increasing temperature, as metabolic processes are faster at higher temperatures, and a critical metabolic imbalance will be reached faster. Models assuming that evaporative water loss determines torpor bout duration (Thomas \& Geiser 1997) make similar predictions. We also predict that subsequent activity will be independent of temperature up to $10^{\circ} \mathrm{C}$. This is because once a critical metabolic imbalance has been reached, the time taken to restore the imbalance while euthermic will be independent of temperature. However, aerial insects become available above $10^{\circ} \mathrm{C}$, and increase in abundance as temperature increases above this threshold (Jones, Duvergé \& Ransome 1995). In summer R. ferrumequinum increases feeding time with increasing temperature (Duvergé 1996). We therefore predict that post-arousal activity will increase with increasing temperature above $10^{\circ} \mathrm{C}$, because more time will be needed to digest the increasing amounts of food captured.

\section{MATERIALS AND METHODS}

The study was carried out in Cheddar Gorge (south-west England: Ordnance Survey Grid reference ST 475545) which has five caves used regularly by $R$. ferrumequinum in winter. The main hibernaculum (Gough’s Old Cave) is approximately $75 \mathrm{~m}$ long and $20 \mathrm{~m}$ deep (Barrington 1964). 
In October, January and April 1995-1997, all hibernating R. ferrumequinum found were sexed, aged, weighed (to the nearest $0.1 \mathrm{~g}$ ), measured and ringed. Twenty-two $R$. ferrumequinum (six each in October 1995 and January 1996, and ten in January 1997) were fitted with pre-calibrated, temperature-sensitive radio-transmitters (BD-2GT; Holohil Systems, Ltd., Carp, Ontario, Canada). The radio-transmitters weighed an average of $1.5 \mathrm{~g}$ (range: 1.3 - $1.8 \mathrm{~g}$ ) and represented on average $6.8 \%$ of the bat's body weight. A small area of fur on the interscapular region was trimmed and the radio-transmitters were secured using Skin-Bond surgical adhesive (Smith and Nephew United, Inc. Largo, Florida, USA). All bats were released one to two hours after capture. To determine if the transmitters affected the bats adversely, percentage loss of condition between surveys was calculated, and that of radio-tagged bats was compared with that of bats not radio-tagged over the same period. A body condition index was calculated, following Speakman \& Racey (1986), as: (body mass (g) / individual forearm (mm)) x $56.0 \mathrm{~mm}$. We have used a modification of their equation (Ransome 1995) using the average forearm length of female $R$. ferrumequinum (56.0mm) to correct for skeletal size differences between bats.

Age was determined, in some cases, from ringing of infants in previous years. The ages of first-year bats not ringed soon after birth were judged from their grey pelage and smoothly tapered epiphyseal-diaphyseal joints in the finger bones (Anthony 1988). Of the 22 . ferrumequinum radiotagged between October 1995 and January 1997, 13 were in their first year (six males, seven females), three were in their second year (two males, one female), and six were between their third and ninth years of age (five males, one female).

A radio-receiver and datalogger (SRX_400 using Event_Log Version 3.1x W-18; Lotek Engineering Inc. Newmarket, Ontario, Canada), connected to a three-element Yagi antenna (Mariner Radar, Lowestoft, UK) was positioned in Gough’s Old Cave, and powered by a 12 v 60 Ah car battery. The receiver scanned for each radio-transmitter every 15 minutes, and if present, its pulse rate (related to body temperature) was recorded. Data were downloaded onto a laptop 
computer every seven to ten days. Efforts were made to minimise disturbance during these short visits to the cave. The bats, however, were disturbed and handled during three annual winter surveys. Any telemetry data collected within the 24 hour period after the day of these surveys were omitted from the analyses.

The radio-receiver and datalogger monitored the temperatures of bats remaining in Gough's Old Cave continuously (i.e. every 15 minutes). Bats that left and hibernated in other caves in Cheddar Gorge were monitored by KJP each night every 30 minutes, from half an hour before, until three hours, or more, after sunset. A second radio-receiver (SRX_400, Lotek) and a three-element Yagi antenna (Mariner Radar) were used for this. Only data from bats monitored continuously were used for statistical analysis of torpor bout duration and arousal timing. Any bats arousing were monitored until they started to re-enter torpor. Activity was monitored throughout the hibernation season which was divided into four winter periods; early winter (mid-October to mid-December), mid-winter (mid-December to mid-February) late winter (mid-February to mid-April) and spring (mid-April to late May).

The time of each arousal, the duration of activity after arousal (from here referred to as activity duration) and the length of each torpor bout were measured. Time of arousal was defined as the time at which the skin temperature of an arousing bat reached $20^{\circ} \mathrm{C}$. Time of re-entry into torpor was defined as the time at which the skin temperature of a bat declined to $20^{\circ} \mathrm{C}$. Activity duration was measured in minutes from time of arousal until time of re-entry into torpor. Bats during this arousal period thermoregulate, normally in the range $34-38^{\circ} \mathrm{C}$ (body temperature). Torpor bout duration was measured in hours from time at re-entry until time at the next arousal.

For each bat, Rayleigh’s test (Batschelet 1981) was used to test if arousal time was randomly distributed. Mean direction represents the mean time of the arousals. Mean vector length $(r)$ is a measure of the concentration of data around the mean, ranging from 0 to 1 with increasing concentration. All times given are Greenwich Mean Times. 
Cave temperature and ambient temperature were measured. Ambient temperature was measured outside each cave at sunset every night using a digital thermometer (accurate to $0.1^{\circ} \mathrm{C}$ ). In order to ascertain whether roosting bats could determine ambient temperature, readings were taken from three locations throughout the cave (Park, Jones \& Ransome 1999). After nightly visits ceased, ambient temperature was calculated from a temperature probe (Tinytalk; Gemini Data Loggers (UK) Ltd, Chichester, accurate to $0.1^{\circ} \mathrm{C}$ ) positioned at the entrance to Gough’s Old Cave. The temperature probe was programmed to measure and store data every 72 minutes.

Analyses were carried out using Sigmastat (SPSS) and Minitab release 9.2 (Ryan, Joiner \& Ryan 1985). Data were tested for normality (Kolmogorov-Smirnov or Ryan-Joiner) and nonparametric methods were adopted where data violated the assumptions of normality.

\section{RESULTS}

Body condition index over winter

The body condition index was calculated for radio-tagged bats and for non radio-tagged bats captured on 18 January 1997 and 5 April 1997. There was no significant difference between the percentage body condition loss of radio-tagged bats and non radio-tagged bats $\left(t_{20}=1.96\right.$, NS). Mean percentage body condition loss for tagged bats was $41.0 \pm 17.1 \%$ (range $=13.3-55.6, n=8$ ), and for non-tagged bats was $51.2 \pm 7.1 \%$ (range $=37.9-63.3, n=14$ ).

\section{Torpor bout duration}

Each of the 22 bats radio-tagged were monitored for an average of $87 \pm 29$ days (mean \pm sd, range: 34 - 147 days). The temperature pattern of six bats is shown in Fig. 1, alongside the cave temperature.

Fig. 1 
A total of 249 torpor bouts were measured, with a mean of $12 \pm 8$ per bat (range $=2-28, n=$ 21 bats). Continuously monitored torpor bouts $(n=179)$ varied from 1.7 - 282.1 hours in duration and the mean torpor bouts of individuals ranged from $30.9 \pm 25.1$ to $177.8 \pm 64.0$ hours.

There was a strong positive correlation between the percentage of radio-tagged bats arousing each night and the ambient temperature (Spearman rank correlation coefficient $r_{s 228}=0.34, P<$ 0.0001). There was, however, considerable variation and bats aroused at all measured ambient temperatures.

It was not possible to analyse the effect of winter period directly, as there were insufficient data to include all the interaction terms in the analysis. Torpor bout durations were, however, divided into winter periods and the analysis repeated in order to determine whether the relationship between ambient temperature and torpor bout duration changed over the course of winter. Over the whole winter, there was a significant negative correlation between ambient temperature and torpor bout duration (Table 1; Fig. 2), and there were no differences among individuals of different age and sex groups. During late winter and spring periods, but not in mid-winter, there was a significant negative correlation between torpor bout duration and mean ambient temperature (Table 1).

Table 1

Fig. 2

\section{Arousal and activity duration}

Body temperatures during torpor ranged from $5^{\circ} \mathrm{C}$ to $16^{\circ} \mathrm{C}$ but most bats maintained a temperature of about $10^{\circ} \mathrm{C}$ throughout winter. The time taken to arouse fully was between 30 and 50 minutes, whereas re-entering torpor usually took two to three hours. A total of 265 activity durations were measured, with a mean of $13 \pm 8$ per bat (range $=2-28, n=21$ bats). On average, activity lasted 4 hours 20 minutes but there was a large amount of variation in its duration, which ranged 
from 37 minutes to 54:24 hours. The mean activity duration of individuals ranged from 2:29 \pm 2:06 hours to 8:58 \pm 6:32 hours. The relationship between ambient temperature and activity duration was not linear, as duration only increased with temperature above approximately $10^{\circ} \mathrm{C}$ (Fig. 3).

Fig. 3

Activity durations were transformed to natural logarithms to achieve normality and divided into occasions when ambient temperature was less or greater than $10^{\circ} \mathrm{C}$. There were no significant differences among individuals of different age and sex groups, and there was a significant effect of ambient temperature on activity duration only when the temperature was $10^{\circ} \mathrm{C}$ or above (Table 2 ).

Table 2

Time of arousal

Data from 11 continuously monitored bats were analysed to investigate the timing of arousal (Fig. 4). The majority (85 \%) of arousals took place between two hours before, and two hours after sunset, with the largest peak occurring within the half hour before sunset.

Fig. 4

All but one of the bats (M3129) showed a non-random distribution of arousal times which were concentrated around the mean sunset time for the monitoring period (Table 3; Fig. 5). M3129 (Fig. 5f) had a mean arousal time of $1957 \mathrm{~h}$ but the $r$ value was lower than for the other bats, indicating a wider spread in arousal times. M3129 was a mature female with high body condition in comparison to the other radio-tagged bats. Another bat, M5095 (Fig. 5e), also with a high body condition, had an early mean time of arousal (1544 h) in relation to sunset. This was due to four arousals that took place between $1346 \mathrm{~h}$ and $0647 \mathrm{~h}$. The change in arousal timing displayed by this 
bat during this period is typical of the free-running state. Overall, however, arousal time for M5095 was not randomly distributed $(P<0.002)$.

Table 3

Fig. 5

Step-down multiple regression analysis of four factors (age, body condition adjusted for age (Ransome 1995), proximity of mean arousal time to dusk and number of recorded arousals) on mean vector length $(r)$, showed that only body condition and proximity of arousal time to dusk were significant factors that influenced the concentration of data around the mean arousal time $(r=2.36$ 0.0684 (condition, g) -0.0008 proximity to dusk (mins); $F_{2,8}=71.5, r^{2}=93 \%, P<0.001$ ). The lower the body condition, the greater the concentration of arousal times around the mean $\left(t_{8}=4.53, P\right.$ $<0.01)$. The closer mean arousal time is to dusk, the less variation there was around the mean arousal time. $\left(t_{8}=4.94, P<0.001\right)$. Moreover, bats in poorer body condition tended to have mean arousal times closer to dusk (proximity to dusk (mins) $=-1305+64.2$ (condition, g), $F_{1,9}=7.86, r^{2}$ $=41 \%, P<0.05$ ). Because all bats were monitored over a similar time-period (mid-January until March or May), these results suggest that condition, rather than season, influences arousal timing.

\section{DISCUSSION}

This is the first study to document accurately the frequency and timing of winter arousals in free-living bats, and the subsequent patterns of activity. Furthermore, our findings allow us to make some inferences about the function of arousals. Only two other studies have followed temperature patterns of free-living bats over winter (Thomas 1995; R. Arlettaz unpublished), but in these a much smaller number of bats was monitored over shorter periods of time. 
Bats fitted with radio-transmitters usually remained in the study caves for long periods, and showed similar rates of body condition loss to those without them. Moreover, visits to the cave to download data did not increase bat activity (Park et al. 1999).

\section{Torpor bout duration}

Torpor bout duration was highly dependent on ambient temperature (see also Ransome 1971). The analyses were unable to test for the effect of winter period upon torpor bout duration. However, late winter 1997 was on average four degrees warmer than late winter 1996, and during this period there was a marked decrease in torpor bout duration for many bats during this period in 1997 but not in 1996 (Park 1998), suggesting that ambient temperature is more important than winter period in determining torpor bout duration. This is supported from a concurrent study of activity monitored using ultrasound detectors over the same period (Park et al. 1999). Torpor bout duration is also therefore dependent on cave temperature, since ambient and cave temperatures are highly correlated (Ransome 1968; Park et al. 1999). Bats therefore could use cave temperature fluctuations to ascertain ambient temperature.

\section{Activity duration}

The longer activity lasts, the higher the energetic cost, though feeding while active will offset some of this cost. Activity duration should therefore be minimised if energy savings are important. Our study demonstrated a striking increase in activity duration only when temperature exceeded $10^{\circ} \mathrm{C}$. Ambient temperature has a considerable effect on insect flight activity with the minimum temperature thresholds for the flight of many insects ranging between $8-17.5^{\circ} \mathrm{C}$ (Taylor 1963 ). When ambient temperature exceeds $10^{\circ} \mathrm{C}$ at dusk, there are likely to be some flying insects available as food (Ransome 1968; Jones et al. 1995). Once this temperature threshold for insect flight activity is reached, arousal duration increases with ambient temperature, as insect availability presumably 
rises. During handling and processing $R$. ferrumequinum in this study regularly produced faeces (R.D. Ransome, unpublished data), indicating that feeding had occurred. Therefore it is likely that the longer periods of activity at high ambient temperatures observed are related to feeding.

\section{Time of arousal}

Torpor bouts have been interpreted as representing an extension of circadian cycles as the period of these cycles may lengthen with a decrease in temperature (Heller, Krilonicz \& Kilduff 1989). All but two hibernating $R$. ferrumequinum in this study consistently aroused around dusk. The circadian rhythm of one bat showed a free-running pattern over a five-week period. If the period of circadian rhythms in these bats were lengthened by low temperatures, neither of these patterns would be expected. Thus in $R$. ferrumequinum, circadian rhythms continue in hibernation and must be temperature-compensated in some way.

Are circadian rhythms in hibernating nocturnal animals entrained to dusk as they are in summer, or do these rhythms free-run and become progressively desynchronised with dusk? Hays, Speakman \& Webb (1992) found that under natural photoperiods and ambient temperatures, circadian rhythms remained entrained to dusk during winter in the bat Plecotus auritus. In contrast, three species of vespertilionid bat hibernating in a cave in Canada aroused at random times over the day (Thomas 1993), and there was no temporal clustering of arousals in M. lucifugus (Thomas 1995). Light-sampling at dusk is thought to be the chief way that bats synchronise their endogenous circadian cycle to a daily light cycle (DeCoursey \& DeCoursey 1964). The short torpor bouts of $R$. ferrumequinum may allow it to reset its biological clock continuously, as suggested for Burramys parvus (mountain pygmy-possum) by Körtner, Song \& Geiser (1998).

That most individuals of $R$. ferrumequinum synchronised arousals with dusk suggests further that foraging is an important factor determining arousal timing, since all other suggested arousal activities could occur at any time. An adaptive explanation of the synchronisation of arousal time 
with the optimum time for feeding is supported by the high level of variation in mean vector length explained by body condition and proximity of arousal time to dusk. Bats with the lowest reserves (and hence the most to gain from synchrony) arouse closest to dusk and show the greatest synchronisation of their arousals. Of the two bats with the highest body condition, one showed a free-running pattern over a five-week period, the other a random pattern of arousal, not synchronised with dusk. These bats may therefore have had no incentive to forage, and hence no need to remain synchronised.

\section{Hibernation ecology}

Why then do bats arouse in winter? Our investigation did not investigate the fundamental biochemical, or physiological reason(s) that necessitate arousals periodically during hibernation torpor (see Willis 1982 for review), but we can make some inferences about the functions of arousals. During arousals males may mate with torpid females (Gebhard 1995). If reproductive activity were a primary purpose of arousals males might be expected to arouse more frequently and for longer compared to females. That there were no differences in the torpor bout or activity duration between bats of different sex or maturity indicates that this is not the case. Bats often remained in their roosting cave while active (Park 1998), indicating that foraging is unlikely to be a primary function of arousals, although it is clearly an important factor determining their timing. There is evidence that $R$. ferrumequinum feeds on mild winter nights (Ransome 1968, 1971). By selecting a roosting position that fluctuates with ambient temperatures, and by maintenance of arousal synchronisation with dusk, $R$. ferrumequinum is able to capitalise on foraging opportunities, when they occur. Individuals with large body reserve levels are less synchronised to dusk arousal, and may not need to forage as much as those with low reserves, or even at all. This study also shows that euthermic activity (i.e. the period during which skin temperature exceeded $20^{\circ} \mathrm{C}$ ) after arousal is much longer than was previously suspected, possibly to reduce the sleep debt that may be 
incurred during hibernation torpor (Daan et al. 1991). There was usually, but not always, standing water in the main study cave that would allow bats to drink without emerging from the cave. We cannot reject the hypothesis that hibernating bats arouse to drink, and our results are consistent with a model which states that bats remain torpid until a threshold level of metabolic (or possibly water) imbalance has been achieved. Because metabolism and water loss increase with increasing temperature, torpor bout duration decreases as a consequence. Once the bats arouse, they remain euthermic for some time, and restoration of metabolic or water imbalance is unlikely to depend on temperature. Above $10^{\circ} \mathrm{C}$, however, the bats feed, and because prey availability then increases with increasing temperature, they remain active for longer to forage and digest food.

Hibernating bat species exposed to consistently long and severe winter climates are unlikely to forage during winter. Their circadian rhythms are predicted to free-run in mid winter. Our work shows that bats still arouse periodically from hibernation even when they are unlikely to feed, drink or mate, and that arousals are normally synchronised to dusk so that foraging opportunities can be exploited if they arise.

\section{ACKNOWLEDGEMENTS}

Thanks to Hugh Cornwell, Manager of Cheddar Showcaves who allowed us access to Gough’s Old Cave, and to Bob Cropper for his work in Cheddar. K.J.P. is particularly grateful to Nancy Vaughan, Kate Barlow, Rob Houston, Adam Britton, Alistair McInnes and Will Strange for their help with fieldwork. Thanks to John Altringham for the loan of a Lotek receiver and the Tinytalk temperature probes, and for his comments on the manuscript. Kate Buchanan and John Speakman improved earlier versions of the manuscript. Thanks also to Don Thomas for his useful advice during the early stages of this study. Innes Cuthill provided helpful statistical advice. Work presented in this paper was carried out under licence from English Nature. K.J.P. was funded by a 
Natural Environmental Research Council studentship, and G.J. by a Royal Society University Research Fellowship.

\section{REFERENCES}

Anthony, E.L.P. (1988) Age determination in bats. Ecological and Behavioral Methods for the Study of Bats (ed. T.H. Kunz), pp. 47-58. Smithsonian Institution Press, Washington D.C. \& London.

Avery, M.I. (1985) Winter activity of pipistrelle bats. Journal of Animal Ecology 54, 721-738.

Barrington, N. (1964) The Caves of Mendip. Dalesman Publishing Co., Lancaster.

Batschelet, E. (1981) Circular Statistics in Biology. Academic Press, New York.

Brigham, R.M. (1987) The significance of winter activity by the big brown bat (Eptesicus fuscus): the influence of energy reserves. Canadian Journal of Zoology 65, 1240-1242.

Burton, R.S. \& Reichman, O.J. (1999) Does immune challenge affect torpor duration? Functional Ecology 13, 232-237.

Daan, S., Barnes, B.M. \& Strijkstra, A.M. (1991) Warming up for sleep? Ground squirrels sleep during arousals from hibernation. Neuroscience Letters 128, 265-268.

DeCoursey, G. \& DeCoursey, P.J. (1964) Adaptive aspects of activity rhythms in bats. Biological Bulletin 126, 14-27.

Duvergé, P.L. (1996) Foraging activity, habitat use, development of juveniles, and diet of the greater horseshoe bat (Rhinolophus ferrumequinum - Schreber 1774) in south-west England. PhD thesis, University of Bristol.

Fisher, K.C. \& Mannery, J.F. (1967) Water and electrolyte metabolism in heterotherms. Mammalian Hibernation volume 3 (eds K.C. Fisher, A.R. Dawe, C.P. Lyman, E. Schönbaum \& F.E. South), pp. 235-279. Oliver \& Boyd, Edinburgh. 
French, A.R. (1985) Allometries of the durations of torpid and euthermic intervals during mammalian hibernation: a test of the theory of metabolic control of the timing of changes in body temperature. Journal of comparative Physiology 156B, 13-19.

Gebhard, J. (1995) Observations on the mating behaviour of Nyctalus noctula (Schreber 1774) in the hibernaculum. Myotis 32/33 123-129.

Hays, G.C., Speakman, J.R. \& Webb, P.I. (1992) Why do brown long-eared bats (Plecotus auritus) fly in winter? Physiological Zoology 65, 554-567.

Heller, H.C., Krilonicz, B.L. \& Kilduff, T.S. (1989) Neural mechanisms controlling hibernation. Living in the Cold volume 2 (eds A. Malan \& B. Canguilhem), pp. 447-459. INSERM/Libby, Paris.

Jones, G., Duvergé, P.L. \& Ransome, R.D. (1995) Conservation biology of an endangered species: field studies of greater horseshoe bats. Symposia of the Zoological Society of London 67, 309324.

Jones, G. \& Rydell, J. (1994) Foraging strategy and predation risk as factors influencing emergence time in echolocating bats. Philosophical Transactions of the Royal Society of London B 346, 445455.

Körtner, G., Song, X. \& Geiser, F. (1998) Rhythmicity of torpor in a marsupial hibernator, the mountain pygmy-possum (Burramys parvus), under natural and laboratory conditions. Journal of comparative Physiology 168B, 631-638.

Lyman, C.P. (1982) Hibernation and Torpor in Mammals and Birds (eds C.P. Lyman, J.S. Willis, A. Malan \& L.C.H. Wang). Academic Press: San Diego, California.

Malan, A. (1989) Living in the cold: 2nd international symposium (eds A. Malan \& B. Canguilhem). INSERM/Libby: Paris.

Michener, G. (1992) Sexual differences in over-winter torpor patterns of Richardson’s ground squirrels in natural hibernacula. Oecologia 89, 397-406. 
Park, K.J. (1998) Roosting ecology and behaviour of four temperate species of bat. $\mathrm{PhD}$ thesis, University of Bristol.

Park, K.J., Jones, G. \& Ransome, R.D. (1999) Winter activity in a population of greater horseshoe bats Rhinolophus ferrumequinum. Journal of Zoology, London 248, 419-427.

Ransome, R.D. (1968) The distribution of the greater horseshoe bat, Rhinolophus ferrumequinum, during hibernation, in relation to environmental factors. Journal of Zoology, London 154, 77-112.

Ransome, R.D. (1971) The effect of ambient temperature on the arousal frequency of the hibernating greater horseshoe bat, Rhinolophus ferrumequinum, in relation to site selection and the hibernation state. Journal of Zoology, London, 164 353-371.

Ransome, R.D. (1995) Earlier breeding shortens life in female greater horseshoe bats. Philosophical Transactions of the Royal Society of London B 350, 153-161.

Ryan, B.F., Joiner, B.I. \& Ryan, T.A. (1985) MINITAB Handbook 2nd Edition. PWS-Kent, Boston Schmidt, J.P. (1967) Response of hibernating mammals to physical, parasitic and infectious agents. Mammalian Hibernation volume 3 (eds K.C. Fisher, A.R. Dawe, C.P. Lyman, E. Schönbaum \& F.E. South), pp. 421-438. Oliver \& Boyd, Edinburgh.

Speakman, J.R. \& Racey, P.A. (1986) The influence of body condition on sexual development of male brown long-eared bats (Plecotus auritus) in the wild. Journal of Zoology, London 210, 515525.

Speakman, J.R. \& Racey, P.A. (1989) Hibernal ecology of the pipistrelle bat: energy expenditure, water requirements and mass loss, implications for survival and the function of winter emergence flights. Journal of Animal Ecology 58, 797-813.

Taylor, L.R. (1963) Analysis of the effect of temperature on insects in flight. Journal of Animal Ecology 32, 99-117.

Thomas, D.W. (1993) Lack of evidence for a biological alarm clock in bats (Myotis spp.) hibernating under natural conditions. Canadian Journal of Zoology 71, 1-3. 
Thomas, D.W. (1995) Hibernating bats are sensitive to nontactile human disturbance. Journal of Mammalogy 76, 940-946.

Thomas, D.W. \& Cloutier, D. (1992) Evaporative water-loss by hibernating little brown bats, Myotis lucifugus. Physiological Zoology 65, 443-456.

Thomas, D.W. \& Geiser, F. (1997) Periodic arousals in hibernating mammals: is evaporative water loss involved? Functional Ecology 11, 585-591.

Thomas, D.W., Dorais, J. \& Bergeron, J.-M. (1990) Winter energy budgets and cost of arousals for hibernating little brown bats, Myotis lucifugus. Journal of Mammalogy 71, 475-479.

Tidemann, C.R. (1982) Sex differences in seasonal changes of brown adipose tissue and activity of the Australian vespertilionid bat Eptesicus vulturnus. Australian Journal of Zoology 30, 15-22.

Trachsel, L., Edgar, D.M. \& Heller, H.C. (1991) Are ground-squirrels sleep-deprived during hibernation. American Journal of Physiology 260, R1123-R1129.

Trayhurn, P. (1993) Brown adipose tissue - from thermal physiology to bioenergetics. Journal of Biosciences 18, 161-173.

Twente, J.W. \& Twente, J.A. (1965) Regulation of hibernating periods by temperature. Proceedings of the National Academy of Sciences of the United States of America 54, 1058-1061.

Twente, J.W. \& Twente, J.A. (1987) Biological alarm clock arouses hibernating big brown bats, Eptesicus fuscus. Canadian Journal of Zoology 65, 1668-1674.

Wang, L.C.H. (1978) Time patterns and metabolic rates of natural torpor in the Richardson's ground squirrel. Canadian Journal of Zoology 57, 149-155.

Willis, J.S. (1982) The mystery of the periodic arousal. Hibernation and Torpor in Mammals and Birds (eds C.P. Lyman, J.S. Willis, A. Malan, L.C.H. Wang), pp. 92-103. Academic Press, San Diego.

Young, P.J. (1990) Hibernating patterns of free-ranging Columbian ground squirrels. Oecologia 83, 504-511. 
Table 1 ANCOVAs for the effects of individual (factor) and mean ambient temperature (covariate) on torpor bout duration (continuously monitored only) over the whole winter, and within separate winter periods (years combined). There were insufficient data to analyse early winter separately. Due to the repeated measures from individuals, the error term for ambient temperature is the adjusted mean square (adj MS) for individual*ambient temperature. Ambient temp. = mean ambient temperature.

\begin{tabular}{llllll}
\hline Analysis & Source & df & adj MS & $F$ & $P$ \\
\hline all winter & individual & 12 & 3391 & 1.04 & NS \\
& ambient temp. & 1 & 147932 & 40.75 & $<0.0001$ \\
& individual*ambient temp. & 12 & 3630 & 1.11 & NS \\
& error & 142 & 3273 & & \\
\hline Winter Period & & & & \\
\hline mid-winter & individual & 6 & 6248 & 2.11 & NS \\
& ambient temp. & 1 & 9933 & 1.85 & NS \\
& individual*ambient temp. & 6 & 5361 & 1.81 & NS \\
& error & 5 & 2956 & & \\
\hline late winter & individual & 10 & 7385 & 1.81 & NS \\
& ambient temp. & 1 & 44111 & 6.38 & $<0.05$ \\
& individual*ambient temp. & 10 & 6911 & 1.69 & NS \\
& error & 66 & 4078 & & \\
\hline spring & individual & 5 & 1329 & 2.28 & NS \\
& ambient temp. & 1 & 25229 & 21.87 & $<0.01$ \\
& individual*ambient temp. & 5 & 1154 & 1.98 & NS \\
& error & 45 & 582 & & \\
\hline
\end{tabular}


Table 2 ANCOVAs for the effects of individual (factor) and ambient temperature under $10^{\circ} \mathrm{C}$ and $10^{\circ} \mathrm{C}$ or above (covariate) on the natural logarithms of activity duration (years combined). Winter period was omitted as a factor as there were insufficient data to include all winter periods in both analyses. Due to the repeated measures from individuals, the error term for ambient temperature is the adjusted mean square (adj MS) for individual*ambient temp.

\begin{tabular}{lllll}
\hline Source (nights $<10^{\circ} \mathrm{C}$ ) & df & adj MS & $F$ & $P$ \\
\hline individual & 16 & 0.1484 & 1.01 & NS \\
ambient temp & 1 & 0.1057 & 0.65 & NS \\
individual*ambient temp. & 16 & 0.1625 & 1.10 & NS \\
error & 55 & 0.1471 & & \\
\hline Source (nights $\geq 10^{\circ} \mathrm{C}$ ) & & & & \\
\hline individual & 5 & 0.9821 & 1.62 & NS \\
ambient temp & 1 & 18.5500 & 19.56 & $<0.01$ \\
individual*ambient temp. & 5 & 0.9485 & 1.56 & NS \\
error & 68 & 0.6070 & & \\
\hline
\end{tabular}


Table 3 Results of Rayleigh’s test for randomness on the arousal times of 11 continuously

monitored bats. Mean sunset, arousal times and vector lengths $(r)$ are given. $\mathrm{M}=$ male, $\mathrm{F}=$ female, $n=$ number of arousals .

\begin{tabular}{cccccccc}
\hline $\begin{array}{c}\text { Bat identity } \\
\text { (ring number) }\end{array}$ & Sex & $\begin{array}{c}\text { Age } \\
\text { (years) }\end{array}$ & $\begin{array}{c}\text { Mean sunset } \\
\text { time (hours) }\end{array}$ & $\begin{array}{c}\text { Mean arousal } \\
\text { time (hours) }\end{array}$ & $\begin{array}{c}\text { Mean vector } \\
\text { length }(r)\end{array}$ & $P$ & $n$ \\
\hline M5096 & M & 1 & 1829 & 1838 & 0.98 & $<0.001$ & 13 \\
M5095 & F & 1 & 1808 & 1544 & 0.63 & $<0.002$ & 13 \\
M5074 & M & 2 & 1823 & 1821 & 0.83 & $<0.001$ & 24 \\
M4967 & M & 1 & 1901 & 1845 & 0.90 & $<0.001$ & 27 \\
M4630 & M & 1 & 1847 & 1825 & 0.94 & $<0.001$ & 23 \\
M4613 & M & 1 & 1841 & 1825 & 0.90 & $<0.001$ & 28 \\
M5049 & F & 2 & 1749 & 1944 & 0.73 & $<0.001$ & 12 \\
M3129 & F & 6 & 1720 & 1957 & 0.52 & NS & 8 \\
M4638 & F & 1 & 1926 & 1903 & 0.90 & $<0.001$ & 21 \\
M4972 & F & 1 & 1819 & 1823 & 0.99 & $<0.001$ & 14 \\
M4626 & F & 1 & 1920 & 1855 & 0.81 & $<0.001$ & 14 \\
\hline
\end{tabular}




\section{FIGURE LEGENDS}

Fig. 1 Skin temperature (upper trace) of six R. ferrumequinum monitored for between three and four months during the winters of 1995/6 (c = M5095, $1^{\text {st }}$ year female) and 1996/7 (a = M4630, $1^{\text {st }}$ year male; $b$ = M5049, 2 year old female; $d=$ M4967, $1^{\text {st }}$ year male; $\mathrm{e}=$ M5074, 2 year old male; $\mathrm{f}=$ M4613, $1^{\text {st }}$ year male). The lower trace represents the cave temperature where the bat was roosting. The straight dashed line indicates periods when the bat was in a cave where it was not monitored continuously by the telemetry datalogger.

Fig. 2 The relationship between mean ambient temperature and torpor bout duration from $21 R$. ferrumequinum. Closed circles $=$ continuously monitored torpor bouts, open circles $=$ noncontinuously monitored torpor bouts. Between two and 28 torpor bouts per bat are shown. Data from the two years were combined. Only continuously monitored torpor bouts were used for statistical analysis (Table 1).

Fig. 3 The relationship between arousal duration and ambient temperature from $20 R$. ferrumequinum. Between two and 28 arousal durations per bat are shown. Data from the two years were combined.

Fig. 4 Distribution of arousal times of continuously monitored bats over the 24 hour clock. Each bar represents the total number of arousals that took place within a half hour band. Arousals taking place after dawn of one day but before sunset are classed as 'before sunset'. Arousals taking place after sunset of one day but before the subsequent dawn are classed as 'after sunset'. The arrow indicates the median emergence time of $R$. ferrumequinum in summer (Jones \& Rydell 1994). Fig. 5 Arousal patterns for six R. ferrumequinum fitted with radio-transmitters on 25 January 1996 (a = M5096, $1^{\text {st }}$ year male; e = M5095, $1^{\text {st }}$ year female) and 18 January 1997 (b = M5074, 2 year old 
male; c = M5049, 2 year old year female; $d=$ M4967, $1^{\text {st }}$ year male; $f=$ M3129, 6 year old female), and monitored continuously for the next 45 - 130 days. Dark lines represent periods when body temperature was above $20^{\circ} \mathrm{C}$. Bats (a) to (d) show the most common pattern, that of dusk arousals, bat (e) shows a free-running pattern over a period of about a month, and bat (f) shows a pattern of random arousal (see Table 3 for statistical details). Vertical dashed lines indicate sunrise times, vertical solid lines, indicate sunset times. 

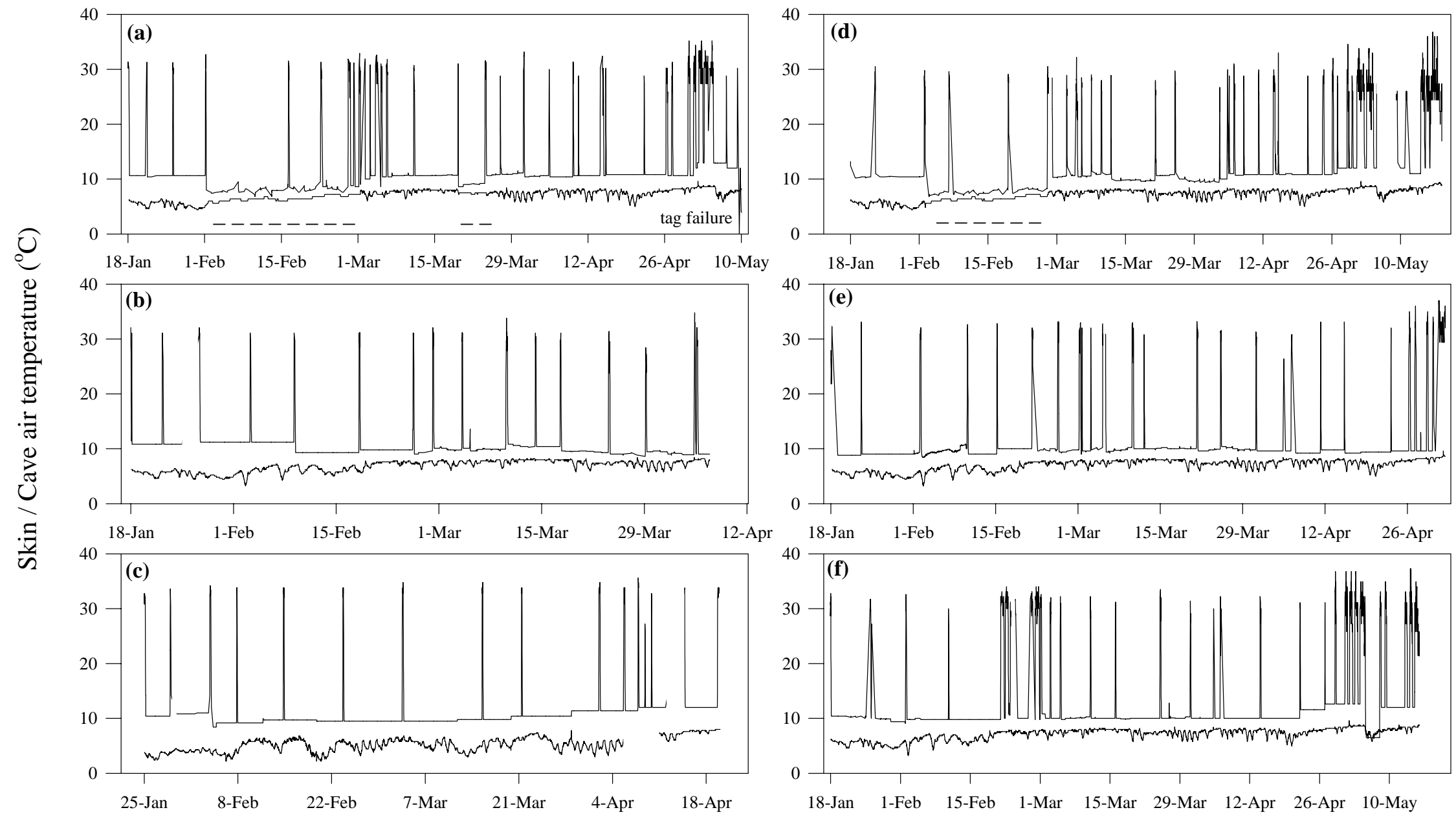

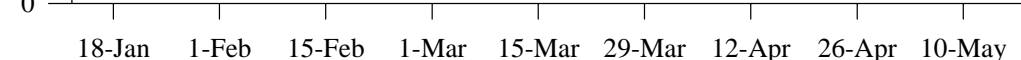
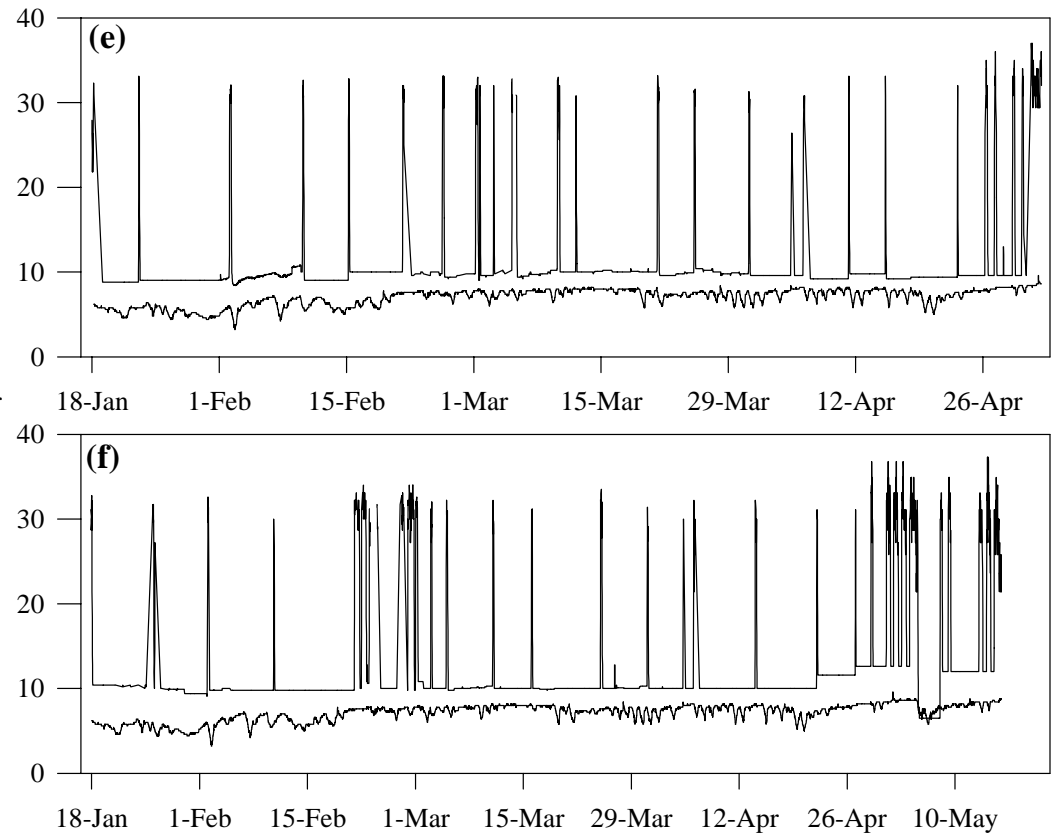

Date

Fig. 1(Park, Jones \& Ransome) 
Fig. 2 (Park, Jones \& Ransome)

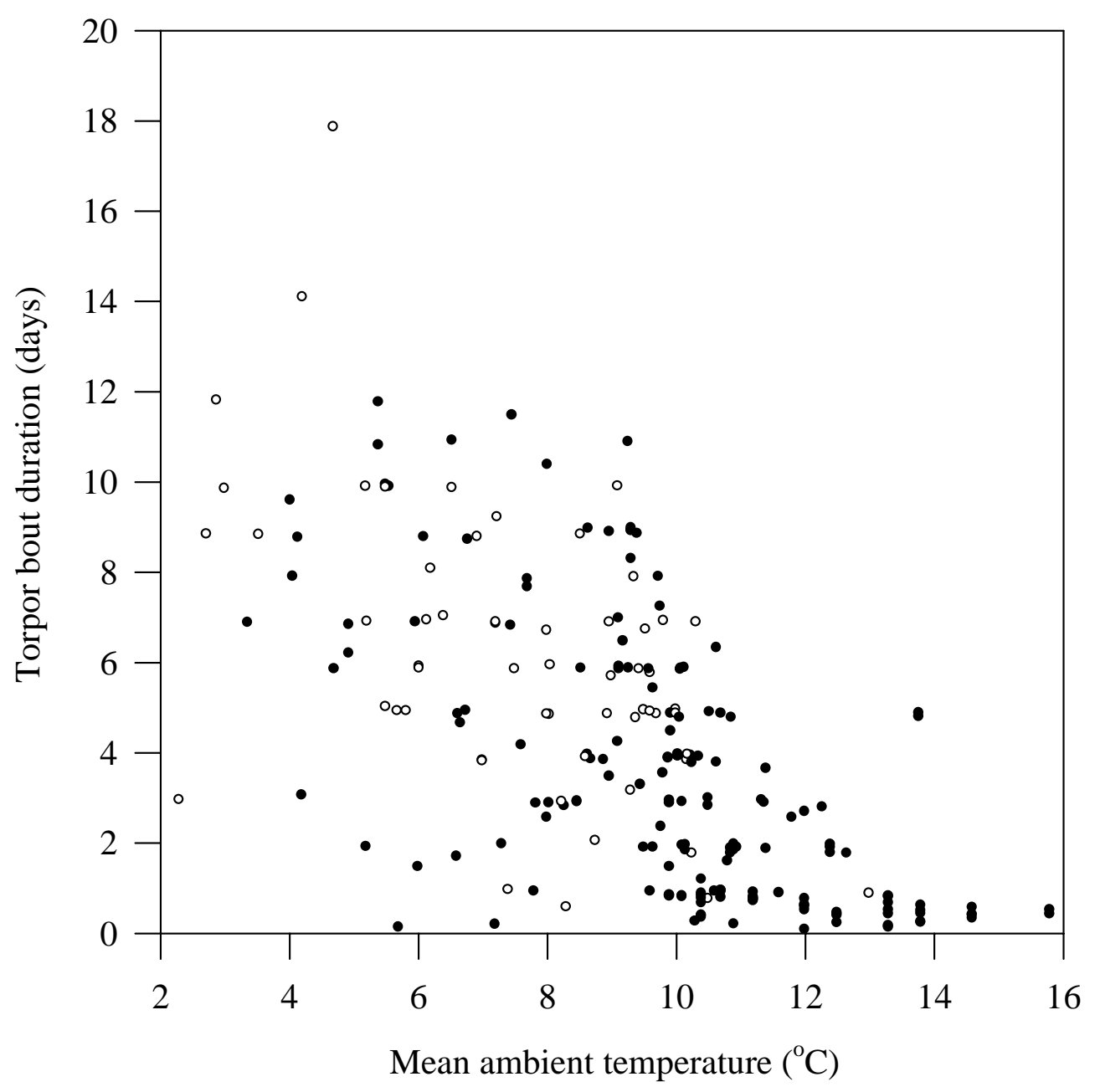


Fig. 3 (Park, Jones \& Ransome)

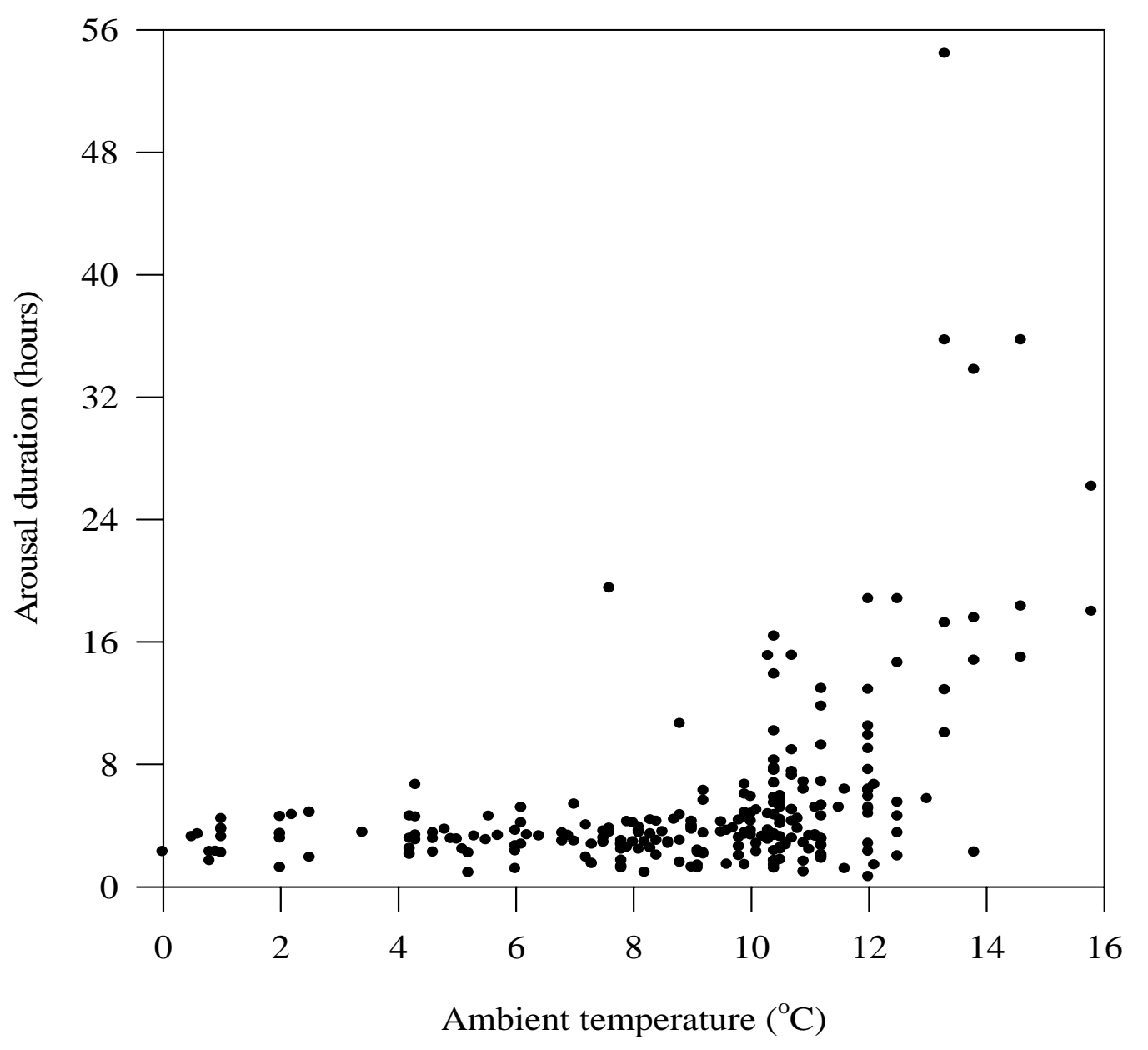


Fig. 4 (Park, Jones \& Ransome)

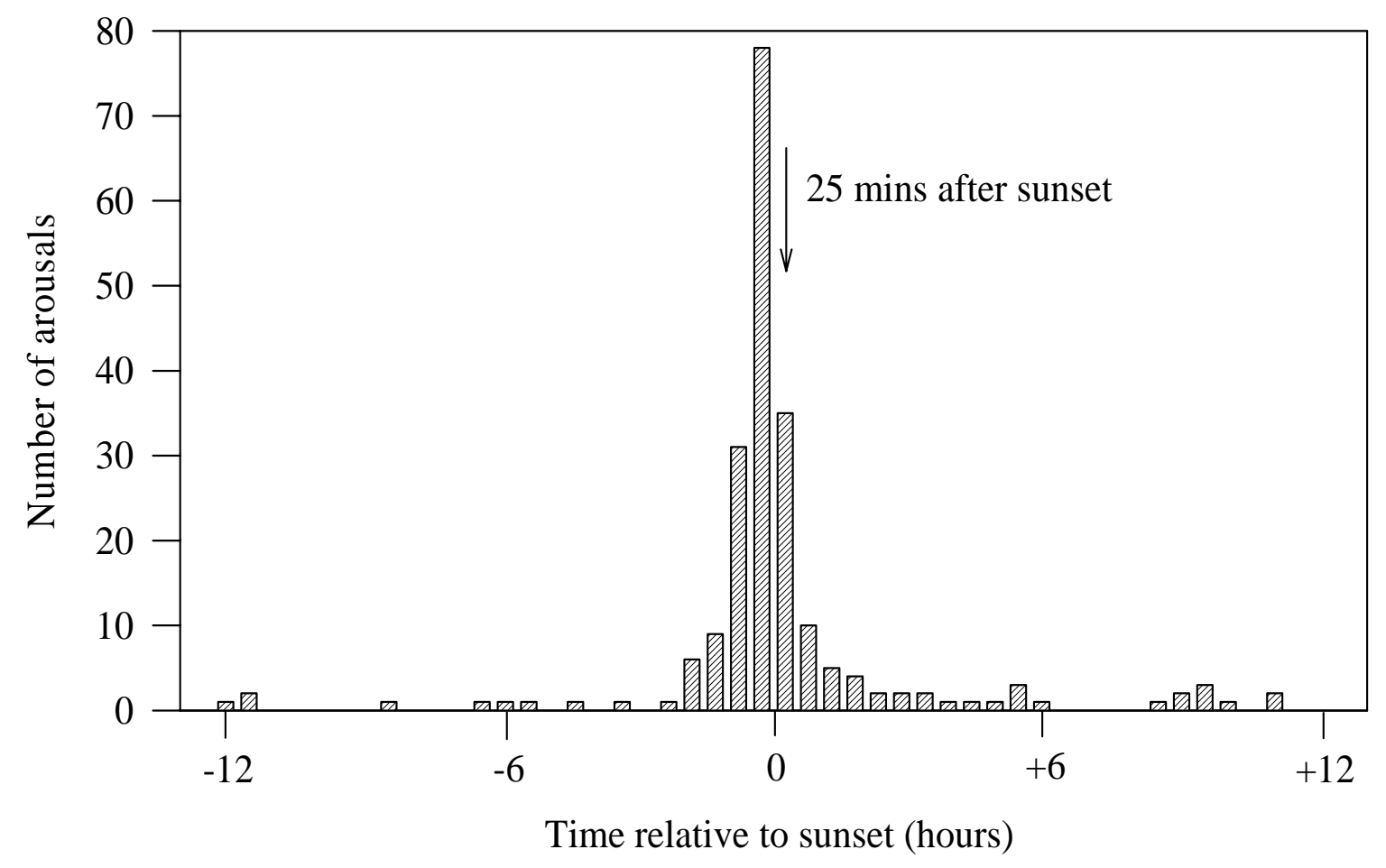


Fig 5 (Park, Jones \& Ransome)
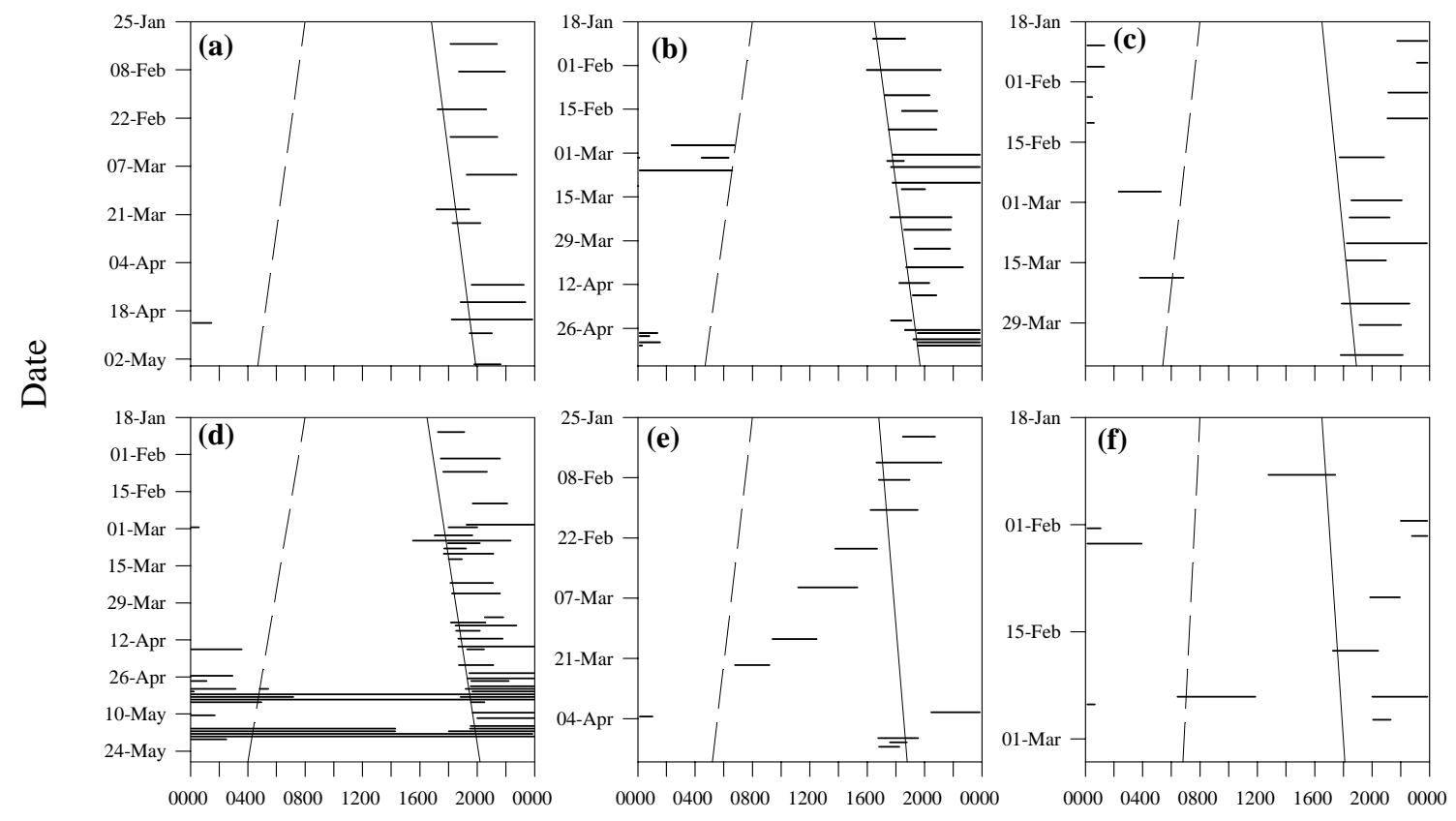

Time of day 